\title{
Performance-based contracting for maintaining transportation assets with emphasis on bridges
}

\author{
Mohammed Alsharqawi ${ }^{1,}{ }^{*}$, Saleh Abu Dabous ${ }^{2}$, and Tarek Zayed ${ }^{1}$ \\ ${ }^{1}$ Concordia University, Department of Building, Civil and Environmental Engineering, Montréal, \\ Québec, Canada \\ ${ }^{2}$ University of Sharjah, Department of Civil and Environmental Engineering, Sharjah, United Arab \\ Emirates
}

\begin{abstract}
With a large number of aging transportation infrastructure assets in North America and the growing problem of deterioration across the globe, managing these assets have been the subject of ongoing research. There is an overwhelming amount of maintenance and rehabilitation works to be done and selecting a suitable maintenance, repair or replacement (MRR) strategy is one of the most challenging tasks for decision makers. Limited budget and resources are even making the decision making process more challenging. Maintaining infrastructure to the highest possible condition while investing the minimal amount of money has promoted innovative contracting approaches. Transportation agencies have increased private sector involvement through long term performance-based maintenance contracts or what is called PerformanceBased Contracting. PBC is a type of contract that pays a contractor based on the results achieved, not on the methods for performing the maintenance work. By looking into the literature, it is observed that agencies are expanding the amount of contracting they do in order to maintain and achieve a better standard of infrastructure facilities. Therefore, the objective of this paper is to study and review performancebased contracting for transportation infrastructure with emphasis on bridge assets.
\end{abstract}

\section{Introduction}

Civil infrastructure systems contribute to social and economic welfare through serving a large number of population and businesses. Bridges are vital components of this civil infrastructure system in terms of mobility, economy, and development of communities. Any failure in these structures may result in both human life and economic loss. Therefore, maintaining these bridges at functional and safe levels is necessary. In North America, large parts of bridges infrastructure were constructed during the 1960's and 1970's. Accordingly, they are facing an increasingly deteriorating problem. There is an overwhelming amount of maintenance, repair, and replacement (MRR) activities to be done

\footnotetext{
*Corresponding author: mohammed.alsharqawi@concordia.ca
} 
but the resources (funding, staffing, equipment) available are too limited and selecting a suitable MRR strategy to achieve a better standard of infrastructure facilities is one of the most challenging tasks for decision makers. Limited budget is even making the decisionmaking process more challenging. The growing needs and limited resources to maintain the transportation networks have resulted in motivating transportation agencies to expand the amount of contracting they do.

With the conventional traditional method-based contracts, the owner agency specifies techniques, methods, materials, quantities, along with the time that the maintenance activities should be executed [1]. This causes a limitation on the use of new materials and innovative techniques and technologies while maintaining the infrastructure asset [2]. Contractors have better competencies of fulfilling required performance level through innovating in such new and unproven technologies [3]. This can be achieved by extending the short maintenance period to a longer period so that the performance levels can be satisfactorily measured over a longer duration. This type of agreement is called Performance-Based Contracting (PBC) which is a type of contract that pays a contractor based on the results achieved, not on the methods for performing the work. Such contracts allow the maintenance contractors to innovate and improve the efficiency of the services provided to public[4]. Incentives are introduced to the contractors, in this type of contact, as an increase of payments owing to exceeding on a pre-defined performance measure. However, the maintenance contractors will be penalized for failing to comply with performance measures or to promptly rectify revealed deficiencies. The objective of this paper is to study and review performance-based contracting for transportation infrastructure with emphasis on bridge assets as an alternative method for maintenance contracting.

\section{Performance-based contracting for maintenance overview}

There has been some movement over the past decade toward a performance-based contract model for maintaining and managing transportation infrastructure. Performance-Based Contracting (PBC) is defined as "a contracting method that provides incentives and/or disincentives to the maintenance contractor to achieve desired outcomes or results; in its purest form, PBC does not detail how, when, or where to do the work." [5]. The hallmark of PBC is that maintenance contractors are paid based on the results achieved and not on the methods utilized for performing the work. By paying contractors incentives and/or disincentives for measured performance instead of the quality of inputs and giving them the flexibility in choosing materials and methods in delivering maintenance services, contractors are encouraged to use new methods and mix quality which fosters innovation and improves the performance of the structure throughout its life. As in the case of PBC, the long-term planning provides the contractor with enough time horizon to deploy new technologies. Further, the contractors are encouraged to eliminate the future need to perform costly corrective maintenance actions by taking timely preventive maintenance ones [6].

Types of performance-based contracts differ according to scope and coverage. The scope refers to the service activities and the addressed assets while the coverage relates to the amount of highway covered and the geographic area [5]. For instance, a PBC can cover either single asset such as only traffic signs, only pavement, only bridges, ... etc. or all assets along a highway corridor. In terms of service activities, PBC may deal with only a single activity (e.g. sign replacement) or a set of related activities (e.g. rest area maintenance). Stankevich et al. [7] stated that the complexity level of a PBC can range from "simple" to "comprehensive" depending on the number of assets and range of services included where a simple PBC may cover a single service and a comprehensive one typically covers all assets and comprise the full range of services needed to manage and 
maintain the contracted corridor. Usually, transportation agencies that are newly practicing PBC find the best approach to first gain experience is by contracting a single activity, a single asset, or one set of related activities in a single maintenance area. Once the agency has acquired experience, it is likely to expand the number of assets under contract, coverage area, and the period of performance. Performance contracts are not limited to maintenance including preventive, routine, periodic, and demand-responsive maintenance as rehabilitation of roads and bridges has been part of many performance-based contracts $[5]$.

\subsection{Historical review of performance-based contracting}

PBC for maintenance was first implemented in the province of British Columbia in Canada. Then, provinces of Ontario and Alberta followed by developing their own performancebased contracts. Later, it has become the backbone of maintenance contracting in Australia, New Zealand, some European countries as Finland and England, and to an increasing degree in other countries including the United States where states of Virginia, Texas, and Florida are leading in this area. Gradually, PBC trends spread to other developed and developing countries worldwide. Anastasopoulos et al. [8] illustrate a map of countries (dark highlighted areas) which implemented PBCs as can be seen in Figure 1. Moreover, transportation agencies in North America and around the globe have developed a variety of methods for undertaking PBC, known by other names such as Performance-Specified Maintenance Contracts in Australia and New Zealand; Asset Management Contract in the US; Area Maintenance Contract in Finland and Ontario, Canada; Managing Agent Contract in the UK; and Contrato de REcuperacion y MAntenimiento (CREMA), which means Contract for Rehabilitation and Maintenance in Argentina [5].

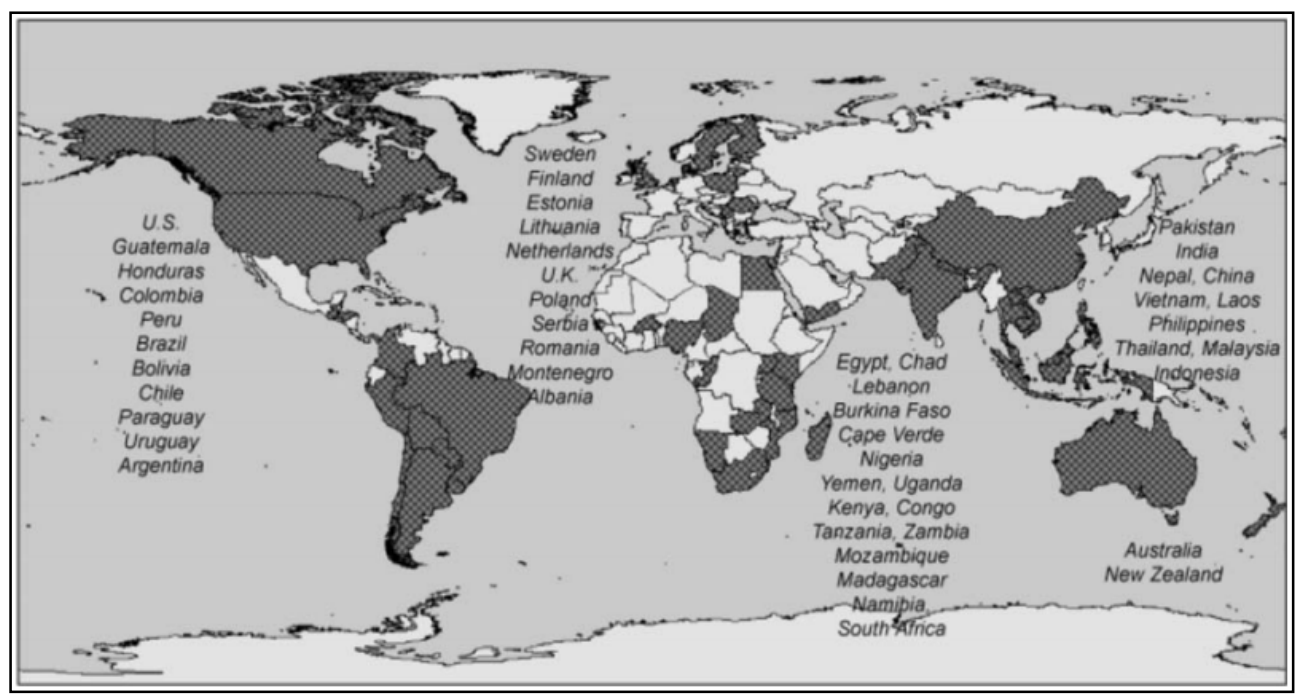

Fig. 1. PBCs implementation worldwide [8].

\subsection{Performance-based contracting framework}

As discussed above, there is a high tendency towards PBC in the area of transportation. In road maintenance, Sultana, M. et al. [9] introduced seven main issues that should be considered by the transportation agencies before applying PBC as shown in Figure 2. The first issue is the transportation agency obligation to define the performance specifications 
and set-up a standard for these performance measures. After that, the agency should check the private sector capability of handling the maintenance to reach the desired LOS quality. Then, the implementation stage takes place where an initial project has to be decided for the performance-based contracts to be applied on. Afterward, a detailed risk analysis has to be done in order to define the events that are out of the maintenance contractors' control and share those risks with the maintenance contractor. Hence, the performance monitoring process takes place where the maintenance contractors are evaluated according to their performance within the contract period. The sixth issue is related to the agency employees as the agency requires fewer people for administrative work and supervision in PBC. The fear of losing job is considered an important issue for the employees and the transportation agency. Finally, the seventh issue is the proper definition of the payment and termination clauses in the contract to avoid any conflicts or disputes that may arise during the contract period.

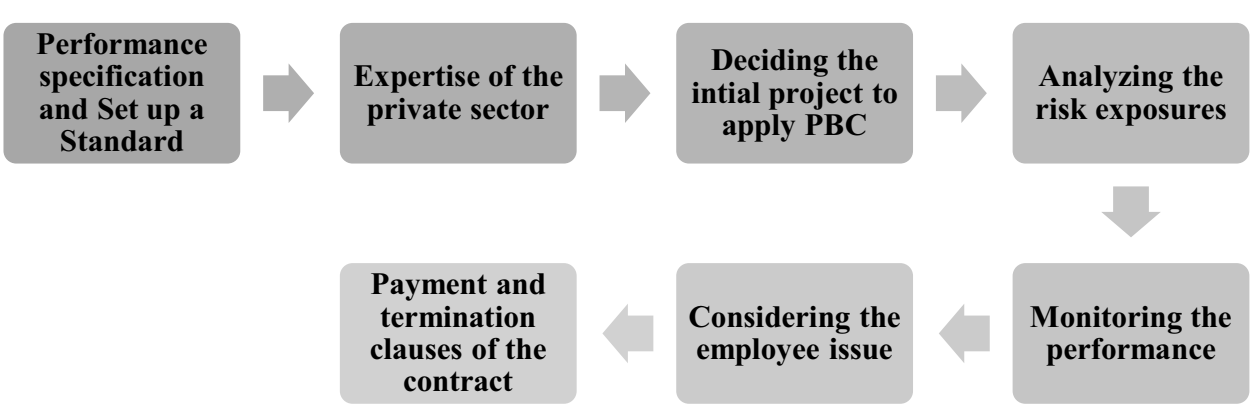

Fig. 2. The seven main issues before applying PBC [9].

\subsection{Benefits of performance-based contracting}

Agencies that have converted to PBC claim cost saving between 10-50\%. Table 1 shows the cost savings of different countries under PBC over the traditional contracts [7]. Moreover, many government agencies reported an $18 \%$ improvement in satisfaction with the maintenance contractors' performance. The agencies added that this price reduction and customer satisfaction took place in several areas from the non-technical, technical, and professional services [10]. Some other advantages found in the literature [5] include but not limited to:

- Improved level of service (could cost more)

- The transfer of risk to the contractor

- More innovation

- More integrated services

- Enhanced asset management

- Ability to reap the benefits of partnering

- Building a new industry

- Achieving economies of scale

\subsection{Risks in Performance-Based Contracting}

In the conventional traditional-based contracts, transportation agencies, called as a client normally, prescribe the techniques, methods, materials specifications, and the time to execute maintenance activities which reduce risks of the maintenance contractors. 
However, this is not the case in performance-based contracts where a contractor is generally free to make decisions of "what to do," "how," and "when" as long as the specified performance measures are achieved $[11,12]$. Hence, the entire risk of any failure or shortcomings of made decisions is transferred to the contractor. Figure 3 depicts the distribution of risk moving from traditional contracting to different forms of contracting. As shown in the figure, agency risks tend to decrease while contractor risks increase when long-term contracts are adopted [13]. The best way of managing the risk associated with such long-term maintenance contracts is to properly i) predict deterioration rates of contracted assets; ii) determine appropriate design, specifications, and materials; iii) plan needed maintenance interventions; iv) estimate quantities [1, 7, 14]; additionally v) inspect and measure the current condition state of contracted assets; and vi) select suitable MRR actions.

Table 1. Cost savings of different countries under PBC over the conventional traditional contracts [7]

\begin{tabular}{|c|c|}
\hline Country & Cost Savings (\%) \\
\hline Norway & About $20 \%-40 \%$ \\
\hline Sweden & About $30 \%$ \\
\hline Finland & About $30 \%-35 \% ;$ about $50 \%$ less cost $/ \mathrm{km}$ \\
\hline Holland & About $30 \%-40 \%$ \\
\hline Estonia & $10 \%$ minimum \\
\hline England & $10 \%-40 \%$ \\
\hline Australia & About $20 \%-30 \%$ \\
\hline New Zealand & $10 \%-15 \%$ \\
\hline USA & About $10 \%$ \\
\hline Ontario, Canada & About $20 \%$ \\
\hline Alberta, Canada & Some, but might be in the order of $10 \%$ \\
\hline British Columbia, Canada & \\
\hline Source:P. Pakkala. & \\
\hline
\end{tabular}

Maintenance contracting has various risks. Types of risks, among others, are identified as follows [5]:

-Poor quality of construction

-Unexpectedly severe weather

-Unanticipated environmental problems

-Emergencies

-Unanticipated legislative change

-Unexpected traffic growth

-A short-term focus that fails to minimize long-term life-cycle costs

-Difficulty in acquiring the resources needed to perform the work (e.g., subcontractors)

-The possibility of having to correct problems covered under a warranty.

However, it is worth noting that the allocation of risks in PBC varies from one country to another [15]. It is essential to identify all the risk variables in order to avoid or mitigate the undesirable consequences such as the first identified risk, poor quality of construction. Thus, the concept of warranty is implemented. The next section aims to provide an overview of the key aspect that is needed before applying PBC which is the performance measures (PMs) that are used to define the levels of service (LOS). 


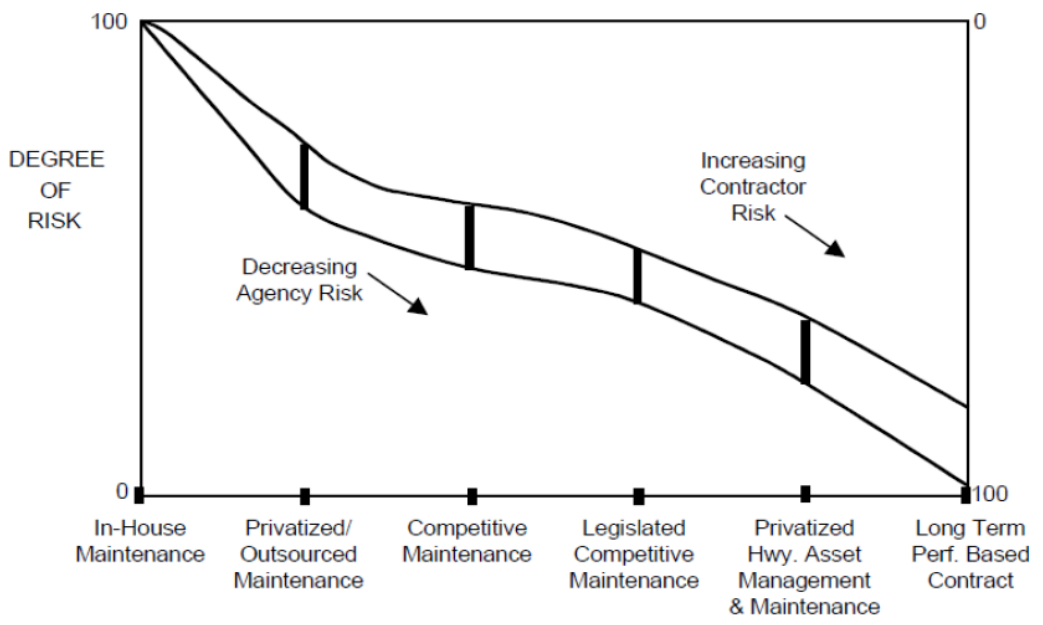

Fig. 3. Distribution of risk with different contract approaches [16].

\section{Performance measures in the PBC}

PBCs can address different types of assets and operations including: pavements, bridges, roadsides, traffic operations, traffic services, incident response, hazardous materials clean up, and emergency repairs [5]. For every type of maintenance and operations, performance measures should be clearly defined and objectively measurable in order to avoid ambiguity and risk disputes [17]. In some countries, measures of performance are often expressed in terms of levels of service represented by specific rating scales corresponding to the condition of different assets. Performance measures (PMs) and performance level of service (LOS) are the basis of a PBC which are expected to be achieved by the maintenance contractor [11]. By looking into the literature, it is observed that many transportation agencies established and defined many performance measures and targets extensively for roads maintenance. However, in the area for bridges management, only a few distinct has addressed these measures. Haas et al. [18, 19] suggested performance indicators for bridges to be the remaining life in years and safety. Many experts on performance measurement argue the benefit of using a few key performance measures instead of many because of the associated simplicity and manageability of those few performance measures [5]. According, performance measures can be defined as a set of outcome-based levels that an agency uses to evaluate the success of the contractor and performance goals are the minimum acceptable levels to be achieved for each performance measure [11].

Performance measures and targets are prescribed in the contract specifications as performance indicators or measures. Performance indicators are measures of quality; quite often the distress indicators which are monitored annually, or more frequently. It is assumed that these indicators give an accurate picture of the asset condition [3]. In general, for a performance measure to be effective, the following questions should be addressed [20]:

- Is the performance measure specific?

- Is the performance measure measurable?

- Is the performance measure achievable?

- Is the performance measure results- oriented?

- Is the performance measure timely?

- Does the measurement meet with the agency's objectives and desires?

- Has the performance been measured before? 
- Does the measurement conflict with the agency's standard specifications?

- Does the measurement aim to improve performance?

A bridge performance measures in a PBC could be categorized into two groups: structural performance and non-structural performance measures. Non-structural performance measures include these non-structural components, such as: bridge guard rails, sound barriers, lighting, signs, drainage system, and bridge cleaning. Structural performance measures are these attributes that indicate the condition or performance of the bridge components, such as cracking, concrete disintegration, steel reinforcement corrosion and expansion joint problems, these assembled can represent the structural condition reliability which is a component's physical condition fitness, an indicator of a component performance state. Therefore, in this research, there liability of the bridge condition is suggested to be one of the key performance indicators or measures to express a bridge's level of service (LOS). Reliability is the base measure for the bridge remaining service life, an indicator that is suggested by Haas et al. $[18,19]$. Other PMs can include but not limited to, bridge railings, lighting, and cleaning. After defining the performance measures, it is equally important to define performance thresholds such that the LOS never exceeds the threshold limit. The client agency specifies these performance thresholds to be met or exceeded during the contract period. This research suggests a threshold of $40 \%$ representing a poor performance state. Further, the client agency can define performance targets or standards where a LOS rating of $80 \%$ for primary systems and $75 \%$ for the secondary systems is desired targets [21].

\section{Performance monitoring of the PBC}

In order to assess the maintenance contractors' performance, de la Garza et al. [4], presented five key components for monitoring $\mathrm{PBC}$ for maintenance and their direct relationship with the overall performance as shown in Figure 4. The identification of these five key components is based on de la Garza et al. [4] study to existing approaches commonly used in the public and private sector for measuring and monitoring performance including the following six approaches: i) ISO 9001:2000 Criteria for Performance Excellence, ii) Malcolm Baldrige National Quality Program, iii) Kaplan and Norton's Balance Scorecard Approach, iv) Mark Graham Brown's Scorecard Approach, v) Department of Energy Performance Measurement Program, and vi) NCHRP 14-12: Highway Maintenance Quality Assurance Program.

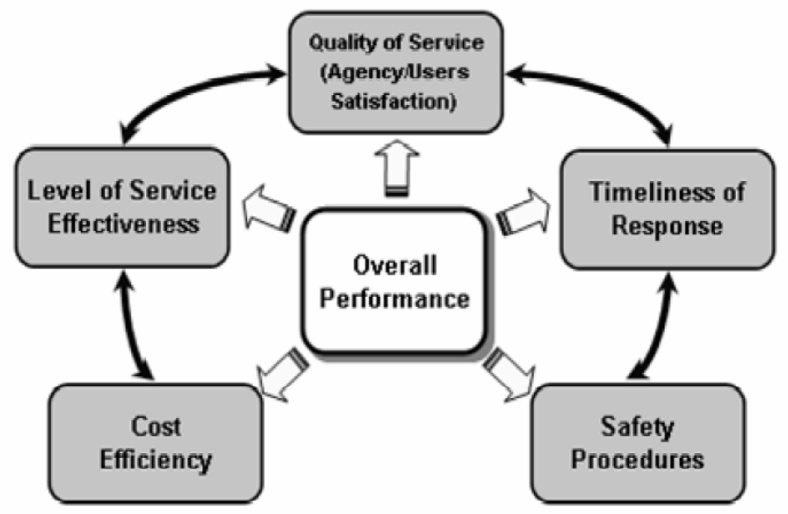

Fig. 4. The five components for monitoring the PBC for road maintenance [4]. 
As shown from the figure, the five main components for monitoring the $\mathrm{PBC}$ are the quality of service, timeless of response, safety procedures, cost-efficiency, and LOS effectiveness [4]. A brief description of each component is as follows:

1- Quality of service evaluates the customers' perception with respect to the condition of the asset and the performance of the maintenance contractor. Customers are the ultimate evaluators of the quality of service provided; therefore, it is extremely important to assess their satisfaction.

2- Timeliness of response assesses the response time of the maintenance contractor to service events or deficient elements as requested by users and need to be attended to in a timely manner.

3- Safety procedures ensure that the maintenance contractor is properly implementing a safety program. It also checks that the maintenance crews performing the work are exposed to minimum risk of accidents.

4- Cost efficiency assesses the cost savings, if any, accrued by the government as a result of engaging a contractor to perform performance-based maintenance services.

5- Level of service effectiveness indicates how far the maintenance contractor is meeting the defined performance criteria and performance targets throughout the contract period.

For instance, if the suggested key performance indicator i.e. bridge reliability fails to meet performance threshold (e.g., LOS $<40 \%$ ) within the warranty period, the maintenance contractor has to repair or rehabilitate the bridge and may also have to pay a penalty for failing to maintain the pre-defined bridge LOS.

\section{Payments system for the PBC}

Payments in performance-based contracts differ significantly from traditional-based contracts. In traditional contracts, payments to contractors are based on the amount of inputs such as number of working hours or quantities; for example, cubic meters of concrete [11]. In contrast, performance-based contracting is a type of contract that pays a contractor based on the results achieved, not on the methods for performing the work. It provides incentives, disincentives, or both to the contractor to achieve desired LOS. In other words, payments for the management and maintenance of assets in this type of contract are explicitly linked to the contractor successfully meeting or exceeding these minimum performance indicators. Failing to comply with the pre-defined performance measures or to promptly rectify revealed deficiencies affects the contractor's payment adversely through a series of clearly defined penalties. Accordingly, a proper payment system that provides incentives, disincentives, or both is needed in PBC.

\section{Summary and conclusions}

Performance-Based Contracting (PBC) is a type of contract that specifies certain clearly defined minimum performance measures that the contractor is required to meet or exceed when delivering maintenance services during the contract period. It has been successfully developed and applied in different countries, showing great cost savings and better level of service. However, in this type of contract, the entire risk of any failure or shortcomings to achieve the desired targets is transferred to the maintenance contractor. Thus, it is important to develop proper performance modeling to avoid or mitigate such risk. The main challenge in $\mathrm{PBC}$ is to define proper performance measures and their thresholds to guarantee an acceptable LOS while performance monitoring. This study suggests bridge condition reliability as a key performance indicator or measure with a minimum LOS rating of 40 as a performance limit. Other six performance measures are identified as well. Since 
maintenance contractors are assessed in terms of performance, not in terms of level of exerted efforts, it is necessary to establish payment criteria including incentives and/or disincentives. The disincentives or incentives can consist of reductions or increases in payments for respectively falling short or exceeding the desired LOS.

\section{References}

1. Z. Alyami, S. Tighe, TRR Journal. 2, 1-10 (2013)

2. K. Panthi, R. U. Farooqui, S. M. Ahmed, ICCIDC-I, 456-463 (2008)

3. K. Panthi, A Methodological Framework for Modeling Pavement Maintenance Costs for Projects with Performance-Based Contracts (2009)

4. J. de la Garza, J. Piñero, M. Ozbek, A Framework for Monitoring Performance-Based Road Maintenance Contracts, 433-441 (2009)

5. W. A. Hyman, NCHRP Synthesis 389: Performance-Based Contracting for Maintenance (2009)

6. D. Gupta, A. Vedantam, J. Azadivar, Optimal contract mechanism design for performance-based contracts (2011)

7. N. Stankevich, N. Qureshi, C. Queiroz, Performance-based Contracting for Preservation and Improvement of Road Assets (2009)

8. P. C. Anastasopoulos, B. G. McCullouch, K. Gkritza, F. L. Mannering, K. C. Sinha, J Infrastruct Sys.16, 251-263 (2010)

9. M. Sultana, A. Rahman, S. Chowdhury, World Acad Sci Eng Technol.62, 350-355 (2012)

10. Office of Federal Procurement Policy (OFPP), Report on the performance-based service contracting pilot project (1998)

11. Z. Alyami, A Two-Phase Maintenance and Rehabilitation Framework for Pavement Assets under Performance Based Contracts (2012)

12. A. S. Al-Kathairi, Performance Based Road Asset Management System, with a case study: Abu Dhabi (2014)

13. C. Queiroz, The World Bank (1999)

14. A. S. Al-Kathairi, A. A. El Halim, Int JRes Sci Manag.11-16 (2014)

15. G. F. Segal, A. T. Moore, S. McCarthy, The Institute. 21 (2003)

16. R. Haas, J. Yeaman, C. Raymond, L. C. Falls, Fifth International Conference on Managing Pavements (2001)

17. G. Zietlow, cutting costs and improving quality through performance-based road management and maintenance contracts (2005)

18. R. Haas, S. Tighe, J. Yeaman, L. C. Falls, Annual Conference of theTransportation Association of Canada (2008)

19. R. Haas, G. Felio, Z. Lounis, L. C. Falls, Annual Conference of the Transportation Association of Canada (2009)

20. SAIC, Performance contracting framework fostered by highways for LIFE (2006)

21. K. L. Smith, M. Stivers, T. E. Horner, A. R. Romaine, NCHRP Web Document 8: Highway Maintenance Quality Assurance (1997) 